\title{
ANALISIS QUALITY CONTROL UNTUK MENJAGA KUALITAS PRODUK KERIPIK UBI UNGU PADA PROSES PRODUKSI (Studi Kasus pada Industri Kecil Menengah SHA-SHA Tanjunganom)
}

\author{
Eka Yeni; Ariadi Santoso; Mohammad Arifin \\ Fakultas Ekonomi - Universitas Kadiri, Kediri \\ Email : ariadi_santoso@unik-kediri.ac.id
}

\begin{abstract}
The objectives of this study are: (1) To determine the quality control of the production process of purple yam chips in the SHA-SHA IKM in an effort to produce quality products that are safe for consumption. (2) To identify potential causes that affect the quality of purple yam chips in the SHA-SHA IKM. (3) To find out the quality control in the production process is controlled or uncontrolled. This study uses a quantitative approach. The sampling method uses purposive sampling method. Methods of collecting data using observation, interviews, and literature. The data analysis method used is Statistical Quality Control (SQC). Based on the results of the study it can be concluded that (1) Quality control in the production process of purple yam chips in the SHA-SHA IKM has produced quality and safe for consumption products (2) The most dominant type of defect in IKM SHA-SHA purple yam chips is defective because of broken fracture (3) Based on the control chart in the production process of the SHA-SHA IKM in January 2018 the CL (central line) value is 0.19 and the value of UCL (upper control limit) is 0.31 while LCL (lower control limit) is 0 , 07). It can be seen that the proportion of defects that occur in the production process of the IKM SHA-SHA purple yam chips in January 2018 (8 observations) is under control because all points are between the control limits.
\end{abstract}

Keywords: Quality Control, Product Quality

\begin{abstract}
ABSTRAK
Tujuan penelitian ini adalah : (1) Untuk mengetahui pengendalian mutu pada proses produksi keripik ubi ungu pada IKM SHA-SHA dalam usaha menghasilkan produk yang bermutu dan aman untuk dikonsumsi. (2) Untuk mengidentifikasi sebab potensial yang mempengaruhi mutu keripik ubi ungu pada IKM SHA-SHA. (3) Untuk mengetahui pengendalian mutu pada proses produksi tersebut terkendali ataupun tidak terkendali. Penelitian ini menggunakan pendekatan kuantitatif. Metode pengambilan sampel menggunakan metode purposive sampling. Metode pengumpulan data menggunakan observasi, wawancara, dan studi pustaka. Metode analisis data yang digunakan adalah Statistical Quality Control (SQC). Berdasarkan hasil penelitian dapat disimpulkan bahwa (1) Pengendalian mutu pada proses produksi keripik ubi ungu pada IKM SHA-SHA telah menghasilkan produk yang bermutu dan aman untuk dikonsumsi (2) Jenis kecacatan yang
\end{abstract}


paling dominan pada produk keripik ubi ungu IKM SHA-SHA adalah cacat karena patah remuk (3) Berdasarkan grafik kendali pada proses produksi IKM SHA-SHA bulan Januari 2018 di dapat nilai CL (central line) sebesar 0,19 dan niali UCL (upper control limit) sebesar 0.31 sedangkan LCL (lower control limit) sebesar 0,07). Dapat dilihat bahwa proporsi cacat (ketidaksesuaian) yang terjadi pada proses produksi keripik ubi ungu IKM SHA-SHA di bulan Januari 2018 (8 kali observasi) dalam keadaan terkendali karena semua titik berada diantara batas kendali.

Kata kunci: Quality Control, Kualitas Produk

\section{PENDAHULUAN}

Pada era industrialisasi saat ini yang kian lebih kompetitif, setiap pelaku usaha ingin berhasil dalam persaingandi sebuah dunia industri yang akan memberikan dampak positif kepada dunia perdagangan. Hal yang dapat dilakukan perusahaan agar dapat bersaing adalah dengan caramenaikan mutu dari hasil produksi, maka sebab itu sebuahindustri harus melakukan pengawasan dan pengendalian kualitas dan menjaga agar kualitas produknya yang dihasilkan terjamin serta diterima konsumen dan dapat bersaing.Pengelolaan dana tergantung pada keputusan pemerintah dengan melihat kondisi yang ada (Puspita \& Santoso, 2017)

Semua konsumen pada umumnya akan mengharapkan produk yang berkualitas dan tersedia keamanannya. Mutu atau kualitas tersebut adalah suatu susunan dari citra sebuah produk atau jasa dengan patokan yang telah ditetapkan dalam sebuah industri berdasarkan dari ketentuan tertentu, keperluan dan harapan dari pelanggan.Keberhasilan dalam bekerja dapat dilihat dari karakteristik seseorang secara team work (Lestari, 2018)

Mutu dari sebuah produk tentunya harusdapat dikendalikan dan dimajukan dengan semestinya, apabila terdapat metode produksi yang kurang tepat. supaya bisa mendapatkan metode produksi yang tepat sebuah industri harus melaksanakan penjagaan atau pengendalian kualitas yang mengarah pada produk yang akan diproduksi.(Noor, 2015)

Dan jika semua rangkaian tindakan produksi sudah dilakukan dengan tepat. tapi pada hal yang sebenarnya masih ditemukan sebuah kekeliruan-kekeliruan dimana kualitas dari produk itu tersebut tidak sepadan dengan kadar mutu yang diinginkan oleh industri perusahaan, hal-hal yang menimbulkan suatu produk tidak sesuai dengan apa yang diinginkan perusahaan ditimbulkan oleh bahan baku, tenaga kerja, dan mesin kerja 
(peralatan), oleh karena itu perusahaan harus lebih fokus terhadap mutu atau kualitas produk yang akan dihasilkan.

Menurut Hendra Kusuma (2016) mengemukakan bahwa "Maksud dari pengawasan serta pengendalian produksi ialah agar dapatmengupayakan dan mengendalikan saluran bahan baku kedalam, di dalam dan keluar pabrik sehingga memperoleh keuntungan tinggi yang merupakan tujuan dari sebuah industridapat diraih."

Pengawasan produksi yang dikehendaki agar mampu mendatangkan hasil sumber daya produksi tertentu dengan cara yang menghasilkan, lebih-lebih dalam hal kegiatan mencukupi harapan dari konsumen serta menghasilkan keuntungan untuk industri.

Usaha aneka keripik, kue dan olahan "SHA-SHA" merupakan usaha yang bergerak di bidang produksi. Proses produksi beragam olahan tersebut berada di dusun Kebonangung desa Sumber Kepuh kecamatan Tanjunganom kabupaten Nganjuk. Awal mulanya usaha pembuatan keripik ibu Ayun berdiri sejak tahun 2006 di Dsn. Kebonagung, Ds. Sumberkepuh, Kec. Tanjunganom, Kab. Nganjuk.

Tabel 1. Data IKM SHA SHA

\begin{tabular}{|l|l|l|l|l|l|l|l|}
\hline No & $\begin{array}{c}\text { TA- } \\
\text { HUN }\end{array}$ & MODAL & $\begin{array}{l}\text { PRODUK } \\
\text { YANG } \\
\text { DIHASIL- } \\
\text { KAN }\end{array}$ & $\begin{array}{l}\text { JUMLAH } \\
\text { PRODUKSI }\end{array}$ & $\begin{array}{l}\text { JUMLAH } \\
\text { KARYA- } \\
\text { WAN }\end{array}$ & $\begin{array}{l}\text { TUJUAN } \\
\text { PEMASA- } \\
\text { RAN }\end{array}$ & $\begin{array}{l}\text { ALAT-ALAT } \\
\text { YANG } \\
\text { MENUN- } \\
\text { JANG }\end{array}$ \\
\hline 1 & 2006 & Rp 300.000 & $\begin{array}{l}\text { Keripik } \\
\text { Pisang }\end{array}$ & $\begin{array}{l}\text { Bungkusan } \\
\text { kecil } \\
\text { Rp.300an }\end{array}$ & $\begin{array}{l}\text { Masih } \\
\text { dikerjakan } \\
\text { sendiri }\end{array}$ & $\begin{array}{l}\text { Warung } \\
\text { disekitar } \\
\text { rumah }\end{array}$ & $\begin{array}{l}\text { Kompor } \\
\text { minyak 3 unit, } \\
\text { bak 3 unit dll }\end{array}$ \\
\hline 2 & 2007 & Rp 800.000 & $\begin{array}{l}\text { Keripik } \\
\text { pisang dan } \\
\text { keripik } \\
\text { pohong }\end{array}$ & $\begin{array}{l}\text { Bungkusan } \\
\text { kecil } \\
\text { Rp.500an } \\
\text { dan pesanan } \\
\text { untuk hari } \\
\text { raya }\end{array}$ & $\begin{array}{l}\text { Satu (1) } \\
\text { orang } \\
\text { karyawan }\end{array}$ & $\begin{array}{l}\text { Warung } \\
\text { disekitar } \\
\text { rumah dan } \\
\text { mlijo }\end{array}$ & $\begin{array}{l}\text { Kompor } \\
\text { minyak 5 unit, } \\
\text { bak 5 unit dll }\end{array}$ \\
\hline 3 & 2008 & $\begin{array}{l}\text { Rp } \\
1.600 .000\end{array}$ & $\begin{array}{l}\text { Keripik } \\
\text { pisang, } \\
\text { keripik } \\
\text { pohong dan } \\
\text { keripik } \\
\text { sukun }\end{array}$ & $\begin{array}{l}\text { Bungkusan } \\
\text { kecil } \\
\text { Rp.500an } \\
\text { bungkusan } \\
\text { besar } \\
\text { Rp.5000an } \\
\text { pesanan }\end{array}$ & $\begin{array}{l}\text { Dua (2) } \\
\text { orang } \\
\text { karyawan, }\end{array}$ & $\begin{array}{l}\text { Warung, } \\
\text { mlijo dan } \\
\text { pasar }\end{array}$ & $\begin{array}{l}\text { Tungku tahu, } \\
\text { wajan } \\
\text { diameter 80 } \\
\text { cm. Bak 7 unit }\end{array}$ \\
& & & & & \\
\end{tabular}




\begin{tabular}{|c|c|c|c|c|c|c|c|}
\hline 4 & 2009 & $\begin{array}{l}\mathrm{Rp} \\
2.400 .000\end{array}$ & $\begin{array}{l}\text { Keripik } \\
\text { pisang, } \\
\text { keripik } \\
\text { pohong, } \\
\text { keripik } \\
\text { sukun, } \\
\text { Keripik } \\
\text { aneka } \\
\text { ubi,Keripik } \\
\text { pangsit dll }\end{array}$ & $\begin{array}{l}\text { Bungkusan } \\
\text { kecil } \\
\text { Rp.400an } \\
\text { bungkusan } \\
\text { besar } \\
\text { Rp.4000an, } \\
\text { pesanan Hari } \\
\text { Raya }\end{array}$ & $\begin{array}{l}\text { Tiga ( } 3 \text { ) } \\
\text { orang } \\
\text { karyawan, } \\
1 \text { sales }\end{array}$ & $\begin{array}{l}\text { Warung, } \\
\text { mlijo, } \\
\text { toko, Pasar, } \\
\text { Kantor }\end{array}$ & $\begin{array}{l}\text { Tungku tahu, } \\
\text { wajan besar, } \\
\text { jedingan }\end{array}$ \\
\hline 5 & 2010 & $\begin{array}{l}\mathrm{Rp} \\
3.200 .000\end{array}$ & $\begin{array}{l}\text { Aneka } \\
\text { keripik, } \\
\text { aneka } \\
\text { manisan, } \\
\text { aneka kue, } \\
\text { aneka } \\
\text { olahan }\end{array}$ & $\begin{array}{l}\text { Bungkusan } \\
\text { kecil } \\
\text { Rp.500an } \\
\text { bungkusan } \\
\text { besar } \\
\text { Rp.5000an , } \\
\text { pesanan Hari } \\
\text { Raya }\end{array}$ & $\begin{array}{l}4 \text { produksi } \\
2 \text { sales }\end{array}$ & $\begin{array}{l}\text { Warung, } \\
\text { mlijo, toko, } \\
\text { Pasar, } \\
\text { Kantor, } \\
\text { toko besar, } \\
\text { Dekranasda }\end{array}$ & $\begin{array}{l}\text { Tungku tahu, } \\
\text { wajan besar, } \\
\text { jedingan, } \\
\text { mesin } \\
\text { pemotong, } \\
\text { spiner }\end{array}$ \\
\hline 6 & $\begin{array}{l}2017 \\
- \\
\text { sekara } \\
\text { ng }\end{array}$ & $\begin{array}{l}\mathrm{Rp} \\
4.000 .000\end{array}$ & $\begin{array}{l}\text { Aneka } \\
\text { keripik } \\
\text { Aneka } \\
\text { Manisan } \\
\text { Aneka kue } \\
\text { Aneka } \\
\text { Olahan }\end{array}$ & $\begin{array}{l}\text { Bungkusan } \\
\text { kecil } \\
\text { Rp.500an } \\
\text { bungkusan } \\
\text { besar } \\
\text { Rp.5000an , } \\
\text { pesanan Hari } \\
\text { Raya }\end{array}$ & $\begin{array}{l}4 \text { produksi } \\
2 \text { sales } \\
\text { dan rekanan } \\
\text { kelompok } \\
\text { tani }\end{array}$ & $\begin{array}{l}\text { Warung, } \\
\text { mlijo, } \\
\text { toko, Pasar, } \\
\text { Kantor, } \\
\text { toko besar, } \\
\text { Dekranasda }\end{array}$ & $\begin{array}{l}\text { Tungku tahu, } \\
\text { wajan besar, } \\
\text { jedingan, box } \\
\text { Mesin } \\
\text { pemotong, } \\
\text { spiner,Facum } \\
\text { fraying }\end{array}$ \\
\hline
\end{tabular}

Sumber: IKM SHA-SHA (2018)

IKM SHA-SHA berusaha dalam industrinya agar bias menjaga dan meningkatkan kualitas produk tersebut, salah satu cara yang dapat dilaksanakan adalah dengan cara mengendalikan proses produksinya. Hal tersebut mendorong IKM SHA-SHA dalam usaha melakukan pengendalian kualitas yang berkaitan dengan menjaga kestabilan produknya mulai dari bahan baku, proses produksi hingga pengemasan sehingga meningkatkan kualitas produk yang dihasilkan dan konsumen memperoleh kepuasan dari seluruh produk IKM SHA-SHA tersebut.

Bersangkutan dengan peristiwa tersebut, maka peneliti tertarik untuk melakukan penelitian tentang “Analisis QualityControl Untuk Menjaga Kualitas Produk Keripik Ubi Ungu pada Proses Produksi.

\section{Rumusan Masalah}

Analisis quality control untuk mencapai standar kualitas sangat berperan penting bagi perusahaan dalam memenuhi produk yang bermutu dan terjamin keamannya untuk dikonsumsi. Atas dasar tersebut, rumusan masalah yang berkaitan dengan penelitian ini adalah: 
1. Bagaimanapengendalian mutu pada proses produksi keripik ubi ungu pada IKMSHASHAdalam usaha menghasilkan produk yang bermutu dan aman untuk dikonsumsi?

2. Apakah sebab-sebab potensial yang mempengaruhi mutu keripik ubi ungu pada IKMSHA-SHA?

3. Apakah pengendalian mutu pada proses produksi tersebut terkendali ataupun tidak terkendali?

\section{Manfaat Penelitian}

Dari hasil penelitian ini diharapkan dapat bermanfaat bagi seluruh pembaca, peneliti selanjutnya dan bagi perusahaan sendiri sebagai referensi dan masukan tentang analisis quality control. Manfaat penelitian ini adalah sebagai berikut:

1. Bagi Penulis :Dengan penelitian yang dilakukan, penulis menjadi lebih mengetahui secara khusus mengenai pengendalian mutu pada sebuah produk, sehingga menambah pengetahuan dan memperoleh bekal untuk terjun ke dunia kerja.

2. Bagi Peneliti Selanjutnya :Bagi peneliti selanjutnya, penelitian ini dapat dijadikan sebagai tambahan informasi dan referensi untuk penelitian yang lebih mendalam kedepannya.

3. Bagi Perusahaan IKM SHA-SHA :Untuk IKM, penelitian ini dapat digunakan sebagai kritikan atau saran tentang pengendalian mutu serta sebagai masukan untuk sistem penunjang keputusan dalam memenuhi kepuasan pelanggan.

\section{TINJAUAN PUSTAKA}

\section{Penelitian Terdahulu}

Tabel 2. Penelitian Terdahulu

\begin{tabular}{|c|c|c|c|c|}
\hline No & $\begin{array}{l}\text { Nama } \\
\text { Peneliti }\end{array}$ & Judul & $\begin{array}{c}\text { Variabel dan Alat } \\
\text { Analisis }\end{array}$ & Hasil Penelitian \\
\hline 1 & $\begin{array}{l}\text { Darsono } \\
(2013)\end{array}$ & $\begin{array}{l}\text { Analisis } \\
\text { Pengendalian } \\
\text { Kualitas Produksi } \\
\text { dalam Upaya } \\
\text { Mengendalikan } \\
\text { Tingkat Kerusakan } \\
\text { Produk }\end{array}$ & $\begin{array}{l}\text { Jenis Peneltian: } \\
\text { Deskriptif Kuantitatif } \\
\text { Variabel: } \\
\text { Pengendalian } \\
\text { Kualitas } \\
\text { (independent) } \\
\text { Tingkat Kerusakan } \\
\text { Produk (dependent) }\end{array}$ & $\begin{array}{l}\text { Hasil penelitian tersebut adalah } \\
\text { bahwa tingkat kerusakan produk yang } \\
\text { terjadi dalam proses produksi pada } \\
\text { PT. Albata tidak melampaui batas } \\
\text { standar t. Jenis kerusakan yang terjadi } \\
\text { pada produk dalam proses produksi } \\
\text { pada PT.Albata yaitu warna tidak } \\
\text { sesuai, komponen pecah, salah } \\
\text { amplas dan salah router. Namun, } \\
\text { dengan penerapan metode }\end{array}$ \\
\hline
\end{tabular}




\begin{tabular}{|c|c|c|c|c|}
\hline & & & $\begin{array}{l}\text { Analisis Data : } \\
\text { Pendekatan SQC }\end{array}$ & $\begin{array}{l}\text { pengecekan ganda / berlapis dalam } \\
\text { mengendalikan kualitas produk } \\
\text { PT.Albata dapat menekan terjadinya } \\
\text { kerusakan produk terbukti. }\end{array}$ \\
\hline 2 & $\begin{array}{l}\text { Zulfani } \\
\text { Noor } \\
(2015)\end{array}$ & $\begin{array}{l}\text { Analisis } \\
\text { QualityControl } \\
\text { Untuk Menjaga } \\
\text { Kualitas Produk } \\
\text { Tempe Pada Usaha } \\
\text { HomeIndustri } \\
\text { Tempe Bapak Joko } \\
\text { Purwanto Di } \\
\text { Kelurahan Lok } \\
\text { Bahu Kecamatan } \\
\text { Sungai Kunjang } \\
\text { Samarinda }\end{array}$ & $\begin{array}{l}\text { Jenis Peneltian: } \\
\text { Deskriptif Kuantitatif } \\
\text { Variabel: } \\
\text { Quality Control } \\
\text { (independent) } \\
\text { Kualitas Produk } \\
\text { (dependent) } \\
\text { Analisis Data : } \\
\text { Pendekatan SQC }\end{array}$ & $\begin{array}{l}\text { Hasil penelitian tersebut adalah } \\
\text { bahwa prosedur pengendalian mutu } \\
\text { (quality control) yang diterapkan } \\
\text { mampu menjaga kualitas produk } \\
\text { tempe. Namun pada kenyataanya } \\
\text { masih terdapat produk dari hasil } \\
\text { produksi yang mengalami kegagalan. } \\
\text { Hal tersebut diakibatkan pada proses } \\
\text { pemeraman antara kedelai dan ragi } \\
\text { yang relatif lambat menyatunya. }\end{array}$ \\
\hline 3 & $\begin{array}{l}\text { MaulidaSil } \\
\text { via Arianti } \\
(2016)\end{array}$ & $\begin{array}{l}\text { Analisis } \\
\text { Pengendalian Mutu } \\
\text { Untuk Mencapai } \\
\text { Standar Kualitas } \\
\text { Produk CornChips } \\
\text { Di Pt. Anugrah Cita } \\
\text { Era Food }\end{array}$ & $\begin{array}{l}\text { Jenis Peneltian: } \\
\text { Deskriptif Kuantitatif } \\
\text { Variabel: } \\
\text { Pengendalian } \\
\text { Kualitas } \\
\text { (independent) } \\
\text { Tingkat Kerusakan } \\
\text { Produk (dependent) } \\
\text { Analisis Data : } \\
\text { Pendekatan SQC }\end{array}$ & $\begin{array}{l}\text { Hasil penelitian tersebut adalah } \\
\text { prosedur pengendalian mutu yang } \\
\text { diterapkan mampu menjaga kualitas. } \\
\text { Namun terdapat ketidaksesuaian yang } \\
\text { menjadi prioritas permasalahan yang } \\
\text { menyebabkan produk corn chips } \\
\text { tidak sesuai dengan standar adalah } \\
\text { butiran jagung pecah yang tinggi } \\
\text { pada proses penerimaan bahan baku } \\
\text { jagung pipil, kadar minyak yang } \\
\text { tinggi pada proses produksi serta } \\
\text { berat produk setelah dikemas yang } \\
\text { over-under pada proses pengemasan } \\
\text { corn chips. Hal ini disebabkan oleh } \\
\text { beberapa faktor primer yaitu faktor } \\
\text { material, mesin dan metode. }\end{array}$ \\
\hline
\end{tabular}

Sumber: Data Diolah (2018)

\section{Landasan Teori}

Menurut Stevenson dan Chuong (2014), dijelaskan bahwa "Manajemen operasi merupakan manajemen dari bagian operasi yang bertanggung jawab untuk menghasilkan barang atau jasa."

Menurut Russel dan Taylor (2011), "Manajemen operasi sering didefinisikan sebagai proses transformasi Input (seperti bahan, mesin, tenaga kerja, manajemen, dan modal diubah menjadi output (barang dan jasa)."

Jadi jelas bahwa manajemen operasional adalah suatu aktivitas proses operasi dan pengawasan dari proses tersebut agar proses tersebut dapat menghasilkan nilai dalambentuk barang maupun jasa yang diinginkan.

Manajemen operasional terintegrasi pada 3 komponen utama yang mendukungdalam proses organisasi, yaitu: 
a. Customer (Pelanggan)

Customer merupakan seseorang yang selalu mengkonsumsi kebutuhan pada sistemmanajemen operasional. Customer merupakan orang yang memiliki peran khusus dimanaselalu memberikan saran serta pendapat di awal dan di akhir sistem manajemen operasionalpaling tidak, perusahaan dengan jelas dapat diidentifikasikan pada segmen pasar dan padasegmen customer itu sendiri. Keefektifitas serta keefisienan fungsi manajemen operasionaltidak dapat terstruktur.

b. Process (Proses)

Sebuah proses dalam perusahaan merupakan hubungan dari semua aktifitas yang diperlukanuntuk mengubah input menjadi output (hasil). Proses menggambarkan keseluruhan input,aktifitas perubahan, dan output pada keseluruhan sistem. Hal itu menandakan hal-hal yangdibutuhkan dalam sebuah kegiatan serta menspesifikasikan bahan apa yang dibutuhkan danseberapa besar jumlahnya. Proses juga menggambarkan kegiatan yang diperlukan untukmengubah input mejadi output. Pada akhirnya seluruh kegiatan pemeriksaan dilakukanuntuk memastikan bahwa semua memenuhi standar kualitas, kuantitas, lead time, atau pembagian waktu. Proses manajemen operasional dapat melibatkan produksi pada sebuahproduk atau jasa.

c. Capacity (Kapasitas)

Saat proses menjelaskan bagaimana sistem manajemen operasional bekerja, kapasitasmendeterminasikan seberapa besar sistem produksi. Untuk kebanyakan orang, kapasitasmengartikan seberapa besar dari hasil yang diproduksi perusahaan, bahkan membatasi hasilper unit dalam satuan waktu.

\section{Pengertian Kualitas}

Menurut Kotler dan Armstrong (2008) beberapa atribut yang menyertai danmelengkapi produk (karakteristik atribut produk) adalah:

\section{Merek (branding)}

Merek (brand) adalah nama, istilah, tanda, simbol, atau rancangan, ataukombinasi dari semua ini yang dimaksudkan untuk mengidentifikasi produk atau jasadari satu atau kelompok penjual dan membedakannya dari produk pesaing.Pemberian merek merupakan masalah pokok dalam strategi produk.Pemberianmerek itu mahal dan memakan waktu, serta dapat membuat produk itu berhasil ataugagal.Nama merek yang baik dapat menambah keberhasilan yang besar pada produk. 


\section{Pengemasan (Packing)}

Pengemasan (packing) adalah kegiatan merancang dan membuat wadah atau pembungkus suatu produk.Pengemasan melibatkan merancang dan membuat wadah atau pembungkus suatu produk.

\section{Kualitas Produk (Product Quality)}

Kualitas Produk (Product Quality) adalah kemampuan suatu produk untukmelaksanakan fungsinya meliputi, daya tahan keandalan, ketepatan kemudahanoperasi dan perbaikan, serta atribut bernilai lainnya. Untuk meningkatkan kualitasproduk perusahaan dapat menerapkan programTotal Quality Manajemen (TQM)Selain mengurangi kerusakan produk, tujuan pokok kualitas total adalah untukmeningkatkan nilai konsumen.

Menurut Alma (2011) "Kualitas adalah keunggulan yang dimiliki oleh produk tersebut.Kualitas dalampandangan konsumen adalah hal yang mempunyai ruang lingkup tersendiri yangberbeda dengan kualitas dalam pandangan produsen saat mengeluarkan suatu produkyang biasa dikenal kualitas sebenarnya.

Menurut Tjiptono (2008), "Kualitas mencerminkan semua dimensi penawaranproduk yang menghasilkan manfaat (benefits) bagi pelanggan. Kualitas suatu produkbaik berupa barang atau jasa ditentukan melalui dimensi-dimensinya." Dimensikualitas produk menurut Tjiptono (2008) adalah:

1. Performance (kinerja), berhubungan dengan karakteristik operasi dasar darisebuah produk.

2. Durability (daya tahan), yang berarti berapa lama atau umur produk yangbersangkutan bertahan sebelum produk tersebut harus diganti. Semakin besarfrekuensi pemakaian konsumen terhadap produk maka semakin besar puladaya produk.

3. Conformance to specifications (kesesuaian dengan spesifikasi), yaitu sejauhmana karakteristik operasi dasar dari sebuah produk memenuhi spesifikasitertentu dari konsumen atau tidak ditemukannya cacat pada produk.

4. Features (fitur), adalah karakteristik produk yang dirancang untukmenyempurnakan fungsi produk atau menambah ketertarikan konsumenterhadap produk.

5. Reliability (reliabilitas), adalah probabilitas bahwa produk akan bekerja denganmemuaskan atau tidak dalam periode waktu tertentu. Semakin kecilkemungkinan terjadinya kerusakan maka produk tersebut dapat diandalkan. 
6. Aesthetics (estetika), berhubungan dengan bagaimana penampilan produk.

7. Perceived quality (kesan kualitas), sering dibilang merupakan hasil daripenggunaan pengukuran yang dilakukan secara tidak langsung karena terdapatkemungkinan bahwa konsumen tidak mengerti atau kekurangan informasi atasproduk yang bersangkutan.

8. Serviceability, meliputi kecepatan dan kemudahan untuk direparasi, sertakompetensi dan keramahtamahan staf layanan.

9. Prinsip Pareto untuk seorang manajer proyek adalah mengingatkan untuk fokus pada $20 \%$ hal-hal yang materi, tetapi tidak mengabaikan $80 \%$ masalah. Berikut Hukum Pareto dalam bentuk visual:

\section{Gambar 1. Prinsip Hukum Pareto}

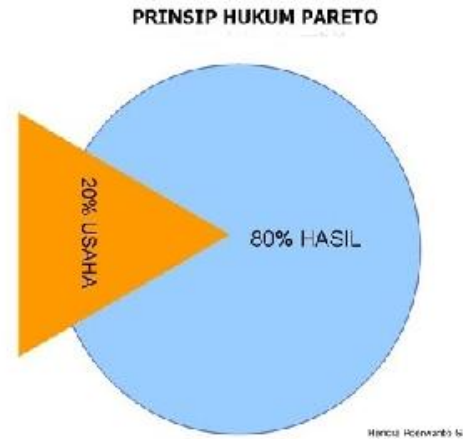

Sumber: https://sites.google.com/site/kelolakualitas/_/rsrc/1379399947482/Diagram-

Pareto/Prinsip\%20hukum\%20pareto.jpg.1379399946914.jpg?height=181\&width=200

Penyusunan Diagram Pareto dapat juga menggunakan tujuh langkah berikut ini:

1. Menentukan metode atau arti dari pengklasifikasian data, misalnya berdasarkan masalah, penyebab jenis ketidaksesuaian, dan sebagainya.

2. Menentukan satuan yang digunakan untuk membuat urutan karakteristik -karakteristik tersebut, misalnya rupiah, frekuensi, unit, dan sebagainya.

3. Mengumpulkan data sesuai dengan interval waktu yang telah ditentukan.

4. Merangkum data dan membuat rangking kategori data tersebut dari yang terbesar hingga yang terkecil.

5. Menghitung frekuensi kumulatif atau persentase kumulatif yang digunakan.

6. Menggambar diagram batang, menunjukkan tingkat kepentingan relatif masingmasing masalah.

7. Mengidentifikasi beberapa hal yang penting untuk mendapat perhatian. 


\section{Kerangka Berpikir}

\section{Gambar 2. Kerangka Berpikir}

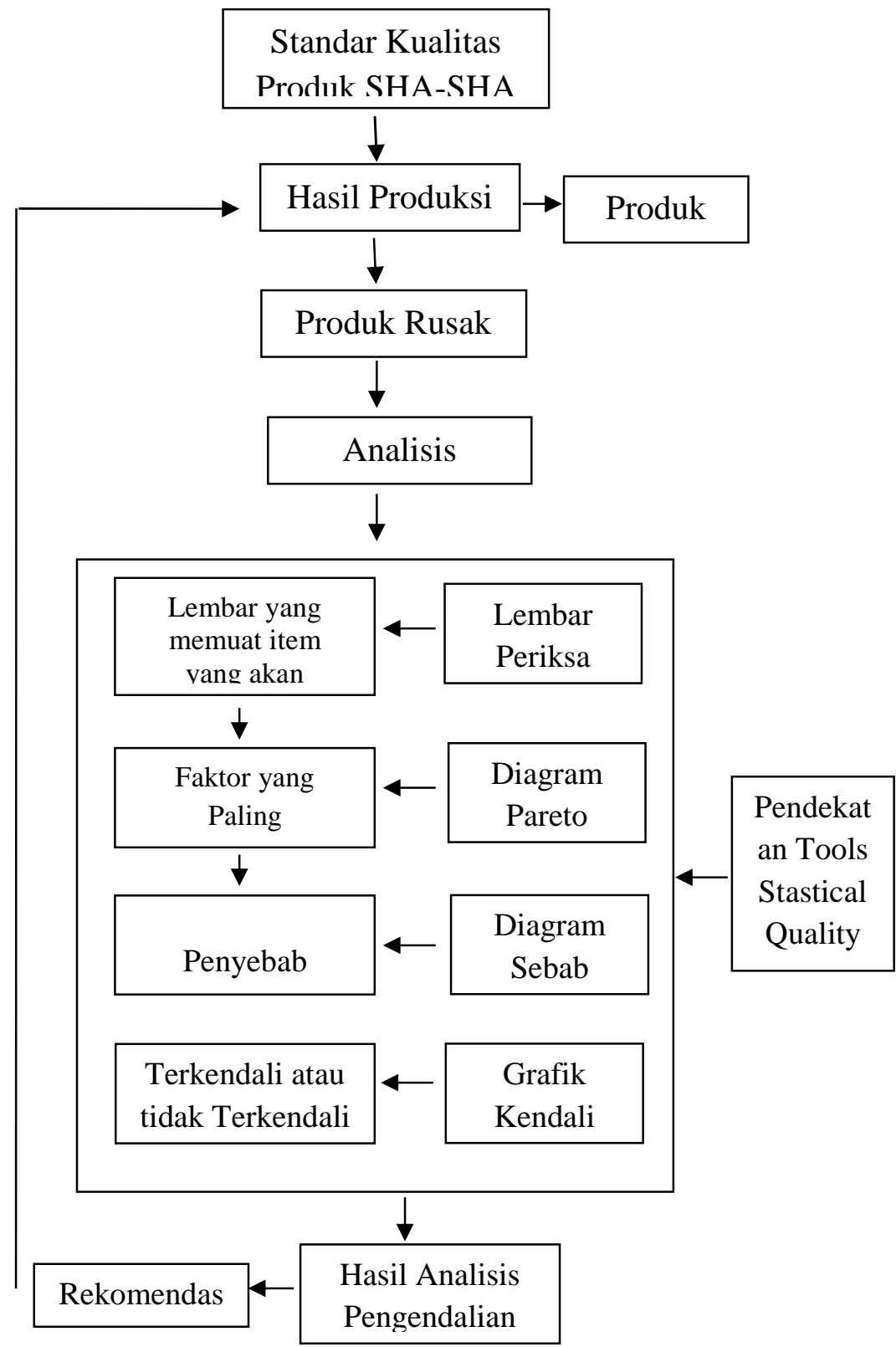

Sumber: Maulida silvia arianti (2016) dan Zulfani Noor (2015) 


\section{METODE PENELITIAN}

\section{Populasi dan Sampel Penelitian}

Populasi merupakan sekumpulan obyek penelitian (orang, benda mati, kejadian) yang memiliki kesamaan dalam satu atau beberapa hal dan yang membentuk masalah pokok dalam suatu riset khusus. Populasi yang akan diteliti hasus di definisikan dengan jelas sebelum penelitian dilakukan (Santoso dan Tjipto, 2002, 79).

Sampel adalah semacam miniatur dari populasi bagian pemilihan sekelompok obyek dari populasi (Santoso dan Tjipto, 2002, 80). Menurut Sugiyono (2016) sampel adalah sebagian dari jumlah dan karakteristik yang di miliki oleh populasi tersebut.Sampel merupakan sebagian atau wakil populasi yang di teliti.

\section{Definisi Operasional}

Wardiyanta (2006:13), menyatakan "definisi operasional adalah suatu informasi ilmiah yang digunakan oleh peneliti untuk mengukur suatu variabel yang merupakan hasil penjabaran dari sebuah konsep.

Tabel 3. Definisi Operasional

\begin{tabular}{|c|c|c|}
\hline Variabel & Definisi Variabel & Indikator \\
\hline $\begin{array}{l}\text { Quality control } \\
\text { (pengendalian } \\
\text { kualitas) }\end{array}$ & $\begin{array}{l}\text { Pengendalian kualitas adalah } \\
\text { teknik dan aktivitas } \\
\text { operasional yang digunakan } \\
\text { untuk memenuhi standar } \\
\text { kualitas yang diharapkan. } \\
\text { Vincent Gasperz (2005:480) }\end{array}$ & $\begin{array}{l}\text { IKM SHA-SHA dalam menjaga kualitas keripik ubi ungu } \\
\text { sebagai berikut: } \\
\text { 1. Memperhatikan pengendalian terhadap pemilihan bahan } \\
\text { baku ubi ungu secara ketat agar tidak terjadi } \\
\text { penyimpangan. } \\
\text { 2. Pengendalian terhadap proses produksi yang berjalan } \\
\text { 3. Pengendalian terhadap proses pengemasan (packing). }\end{array}$ \\
\hline Kualitas produk & $\begin{array}{l}\text { kualitas dapat diartikan } \\
\text { sebagai kondisi dinamis yang } \\
\text { berhubungan dengan produk } \\
\text { jasa, sumber daya manusia, } \\
\text { proses dan lingkungan yang } \\
\text { memenuhi atau melebihi } \\
\text { harapan.(Tjiptono, 2012) }\end{array}$ & $\begin{array}{l}\text { Adapun IKM } S H A-S H A \text { menggunakan delapan karakteristik } \\
\text { ketidaksesuaian produk: } \\
\text { Pada proses pemilihan bahan baku } \\
\text { 1. Ubi ungu yang berjamur } \\
\text { 2. Ubi ungu yang berlubang } \\
\text { Pada proses produksi } \\
\text { 1. Kadar minyak terlalu tinggi } \\
\text { 2. Pemotongan terlalu tebal } \\
\text { 3. Gosong (overcook) } \\
\text { Pada proses pengemasan(packing) } \\
\text { 1. Press bocor } \\
\text { 2. Overload } \\
\text { 3. Remuk }\end{array}$ \\
\hline
\end{tabular}




\section{HASIL PENELITIAN DAN PEMBAHASAN}

\section{Hasil Penelitian}

\section{Pengendalian Mutu Pada Proses Produksi}

Proses produksi merupakan kegiatan untuk menciptakan dan menambah kegunaan suatu barang atau jasa dengan menggunakan faktor-faktor yang ada seperti tenaga kerja, mesin, bahan baku dan dana agar lebih bermanfaat bagi kebutuhan manusia. Pada IKM $S H A-S H A$ ini proses produksi dilakukan setiap hari dan untuk menghasilkan produk keripik ubi unguterdiri dari beberapa tahap proses produksi. Proses diawali dari penerimaan bahan baku, kemudian ke tahap-tahap produksi dan yang terakhir tahap pengemasan. Berikut proses produksi keripik ubi ungu pada IKM SHA-SHA:

1. Pembelian bahan baku (ubi ungu)

Ubi ungu yang dibeli harus yang layak, tidak busuk dan tidak berlubang

2. Pengupasan

Kulit ubi ungu di kupas hingga bersih.

3. Pengirisan

Pada proses pemotongan panjangnya produk disesuaikan dengan kebutuhan, tidak terlalu tebal dan tidak terlalu panjang.

4. Pencucian

Setelah ubi ungu di iris dengan kebutuhan, selanjutnya dilakuan proses pencucian yang bertujuan untuk menghilangkan getah dari ubi ungu. Proses pencucian dilakukan dengan menggunakan air bersih.

5. Pembumbuan

Setelah ubi ungu dicuci bersih kemudian ditiriskan dan di bumbui. Bumbu yang digunakan dalam keripik ubi ungu adalah putih bawang putih dan garam.Pada tahapan ini tingkat kerataan bumbu harus diperhatikan agar rasa produk keripik ubi unguini dapat diterima oleh konsumen.

6. Penggorengan

Ubi ungu yang telah di bumbui akan langsung masuk ke penggorengandan akan dilakukan proses penggorengan dengan dengan minyak panas sampai ubi ungu matang.

7. Penirisan minyak 
Keripik ubi ungu yang sudah matang harus melewati proses penirisan minyakyang tujuan untuk menghisap minyak dan mengurangi kadar air yang terkandung dalam produk tersebut sehingga kadar minyak dan kadar air yang terkandung menjadi lebih rendah.

8. Packing

Keripik ubi ungu ini lalu dikemas dengan ukuran kemasan Rp. 5000,-. Saat pengepressan perlu diperhatikan agar press tidak bocor, keripik tidak overload dan remuk.

Setelah prosedur telah dilaksanakan maka dalam menjaga kualitas keripik ubi ungu IKM SHA-SHA mempertahankan langkah-langkah supaya keripik ubi ungu yang dihasilkan dapat terjaga yaitu sebagai berikut:

1. Memperhatikan pengendalian terhadap pemilihan bahan baku ubi ungu secara ketat agar tidak terjadi penyimpangan.

2. Pengendalian terhadap proses produksi yang berjalan

3. Pengendalian terhadap proses pengemasan (packing).

Penganalisisan data yang diperoleh melalui pengamatan dan wawancara pada usaha pembuatan keripik ubi ungu pada IKM SHA-SHA dan dilakukan dengan menggunakan analisis statistik.Alat analisis statistik dilakukan berdasarkan data dengan metode Statistical Quality Control (SQC). Untuk memudahkan dan mempercepat perhitungan hasil analisis, adapun langkah-langkah yang digunakan sebagai berikut:

1. Mengumpulkan data menggunakan check sheet

2. Mengetahui faktor yang paling mempengaruhi mutu menggunakan diagram pareto.

3. Membuat diagram sebab akibat untuk mengetahui penyebab masalah yang paling mempengaruhi mutu.

4. Membuat grafik kendali untuk mengetahui apakah proses produksi selama bulan Januari terkendali ataupun tidak terkendali. 
Tabel 4. Proses Produksi Keripik Ubi Ungu IKM SHA SHA

\begin{tabular}{|c|c|c|c|c|}
\hline $\begin{array}{l}\text { TANGGAL } \\
\text { OBSERVASI }\end{array}$ & JENIS KETIDAKSESUAIAN & $\begin{array}{l}\text { MEMENUHI } \\
\text { STANDAR }\end{array}$ & $\begin{array}{c}\text { TIDAK } \\
\text { MEMENUHI } \\
\text { STANDAR }\end{array}$ & $\begin{array}{l}\text { PROPORSI } \\
\text { CACAT }\end{array}$ \\
\hline \multirow[t]{11}{*}{$\begin{array}{l}\text { 02 Januari } \\
2018\end{array}$} & $\begin{array}{l}\text { PROSES PEMILIHAN BAHAN } \\
\text { BAKU (UBI UNGU) }\end{array}$ & & & \multirow[t]{7}{*}{0,19} \\
\hline & UBI YANG BERLUBANG & $100 \%$ & $0 \%$ & \\
\hline & UBI YANG BERJAMUR & $100 \%$ & $0 \%$ & \\
\hline & PROSES PRODUKSI & & & \\
\hline & KADAR MINYAK YANG TINGGI & $96 \%$ & $4 \%$ & \\
\hline & PEMOTONGAN TERLALU TEBAL & $96 \%$ & $4 \%$ & \\
\hline & GOSONG / OVERCOOK & $96 \%$ & $4 \%$ & \\
\hline & PROSES PENGEMASAN & & & \\
\hline & PRESS BOCOR & $100 \%$ & $0 \%$ & \\
\hline & OVERLOAD & $100 \%$ & $0 \%$ & \\
\hline & REMUK & $93 \%$ & $7 \%$ & \\
\hline \multirow[t]{11}{*}{$\begin{array}{l}\text { 03 Januari } \\
2018\end{array}$} & $\begin{array}{l}\text { PROSES PEMILIHAN BAHAN } \\
\text { BAKU (UBI UNGU) }\end{array}$ & & & \multirow[t]{11}{*}{0,21} \\
\hline & UBI YANG BERLUBANG & $100 \%$ & $0 \%$ & \\
\hline & UBI YANG BERJAMUR & $100 \%$ & $0 \%$ & \\
\hline & PROSES PRODUKSI & & & \\
\hline & KADAR MINYAK YANG TINGGI & $95 \%$ & $5 \%$ & \\
\hline & PEMOTONGAN TERLALU TEBAL & $95 \%$ & $5 \%$ & \\
\hline & GOSONG / OVERCOOK & $94 \%$ & $6 \%$ & \\
\hline & PROSES PENGEMASAN & & & \\
\hline & PRESS BOCOR & $100 \%$ & $0 \%$ & \\
\hline & OVERLOAD & $100 \%$ & $0 \%$ & \\
\hline & REMUK & $95 \%$ & $5 \%$ & \\
\hline \multirow[t]{11}{*}{$\begin{array}{l}\text { 09 Januari } \\
2018\end{array}$} & $\begin{array}{l}\text { PROSES PEMILIHAN BAHAN } \\
\text { BAKU (UBI UNGU) }\end{array}$ & & & \multirow[t]{11}{*}{0,19} \\
\hline & UBI YANG BERLUBANG & $100 \%$ & $0 \%$ & \\
\hline & UBI YANG BERJAMUR & $100 \%$ & $0 \%$ & \\
\hline & PROSES PRODUKSI & & & \\
\hline & KADAR MINYAK YANG TINGGI & $96 \%$ & $4 \%$ & \\
\hline & PEMOTONGAN TERLALU TEBAL & $96 \%$ & $4 \%$ & \\
\hline & GOSONG / OVERCOOK & $96 \%$ & $4 \%$ & \\
\hline & PROSES PENGEMASAN & & & \\
\hline & PRESS BOCOR & $100 \%$ & $0 \%$ & \\
\hline & OVERLOAD & $100 \%$ & $0 \%$ & \\
\hline & REMUK & $93 \%$ & $7 \%$ & \\
\hline
\end{tabular}




\begin{tabular}{|c|c|c|c|c|}
\hline \multirow[t]{11}{*}{$\begin{array}{l}10 \text { Januari } \\
2018\end{array}$} & $\begin{array}{l}\text { PROSES PEMILIHAN BAHAN } \\
\text { BAKU (UBI UNGU) }\end{array}$ & & & \multirow[t]{11}{*}{0,19} \\
\hline & UBI YANG BERLUBANG & $100 \%$ & $0 \%$ & \\
\hline & UBI YANG BERJAMUR & $100 \%$ & $0 \%$ & \\
\hline & PROSES PRODUKSI & & & \\
\hline & KADAR MINYAK YANG TINGGI & $93 \%$ & $7 \%$ & \\
\hline & PEMOTONGAN TERLALU TEBAL & $96 \%$ & $4 \%$ & \\
\hline & GOSONG / OVERCOOK & $96 \%$ & $4 \%$ & \\
\hline & PROSES PENGEMASAN & & & \\
\hline & PRESS BOCOR & $100 \%$ & $0 \%$ & \\
\hline & OVERLOAD & $100 \%$ & $0 \%$ & \\
\hline & REMUK & $96 \%$ & $4 \%$ & \\
\hline \multirow[t]{11}{*}{$\begin{array}{l}16 \text { Januari } \\
2018\end{array}$} & $\begin{array}{l}\text { PROSES PEMILIHAN BAHAN } \\
\text { BAKU (UBI UNGU) }\end{array}$ & & & \multirow[t]{11}{*}{0,19} \\
\hline & UBI YANG BERLUBANG & $100 \%$ & $0 \%$ & \\
\hline & UBI YANG BERJAMUR & $100 \%$ & $0 \%$ & \\
\hline & PROSES PRODUKSI & & & \\
\hline & KADAR MINYAK YANG TINGGI & $96 \%$ & $4 \%$ & \\
\hline & PEMOTONGAN TERLALU TEBAL & $96 \%$ & $4 \%$ & \\
\hline & GOSONG / OVERCOOK & $96 \%$ & $4 \%$ & \\
\hline & PROSES PENGEMASAN & & & \\
\hline & PRESS BOCOR & $100 \%$ & $0 \%$ & \\
\hline & OVERLOAD & $100 \%$ & $0 \%$ & \\
\hline & REMUK & $93 \%$ & $7 \%$ & \\
\hline \multirow[t]{11}{*}{$\begin{array}{l}17 \text { Januari } \\
2018\end{array}$} & $\begin{array}{l}\text { PROSES PEMILIHAN BAHAN } \\
\text { BAKU (UBI UNGU) }\end{array}$ & & & \multirow[t]{11}{*}{0,17} \\
\hline & UBI YANG BERLUBANG & $100 \%$ & $0 \%$ & \\
\hline & UBI YANG BERJAMUR & $100 \%$ & $0 \%$ & \\
\hline & PROSES PRODUKSI & & & \\
\hline & KADAR MINYAK YANG TINGGI & $95 \%$ & $5 \%$ & \\
\hline & PEMOTONGAN TERLALU TEBAL & $96 \%$ & $4 \%$ & \\
\hline & GOSONG / OVERCOOK & $96 \%$ & $4 \%$ & \\
\hline & PROSES PENGEMASAN & & & \\
\hline & PRESS BOCOR & $100 \%$ & $0 \%$ & \\
\hline & OVERLOAD & $100 \%$ & $0 \%$ & \\
\hline & REMUK & $96 \%$ & $4 \%$ & \\
\hline \multirow[t]{4}{*}{$\begin{array}{l}23 \text { Januari } \\
2018\end{array}$} & $\begin{array}{l}\text { PROSES PEMILIHAN BAHAN } \\
\text { BAKU (UBI UNGU) }\end{array}$ & & & \multirow[t]{4}{*}{0,19} \\
\hline & UBI YANG BERLUBANG & $100 \%$ & $0 \%$ & \\
\hline & UBI YANG BERJAMUR & $100 \%$ & $0 \%$ & \\
\hline & PROSES PRODUKSI & & & \\
\hline
\end{tabular}




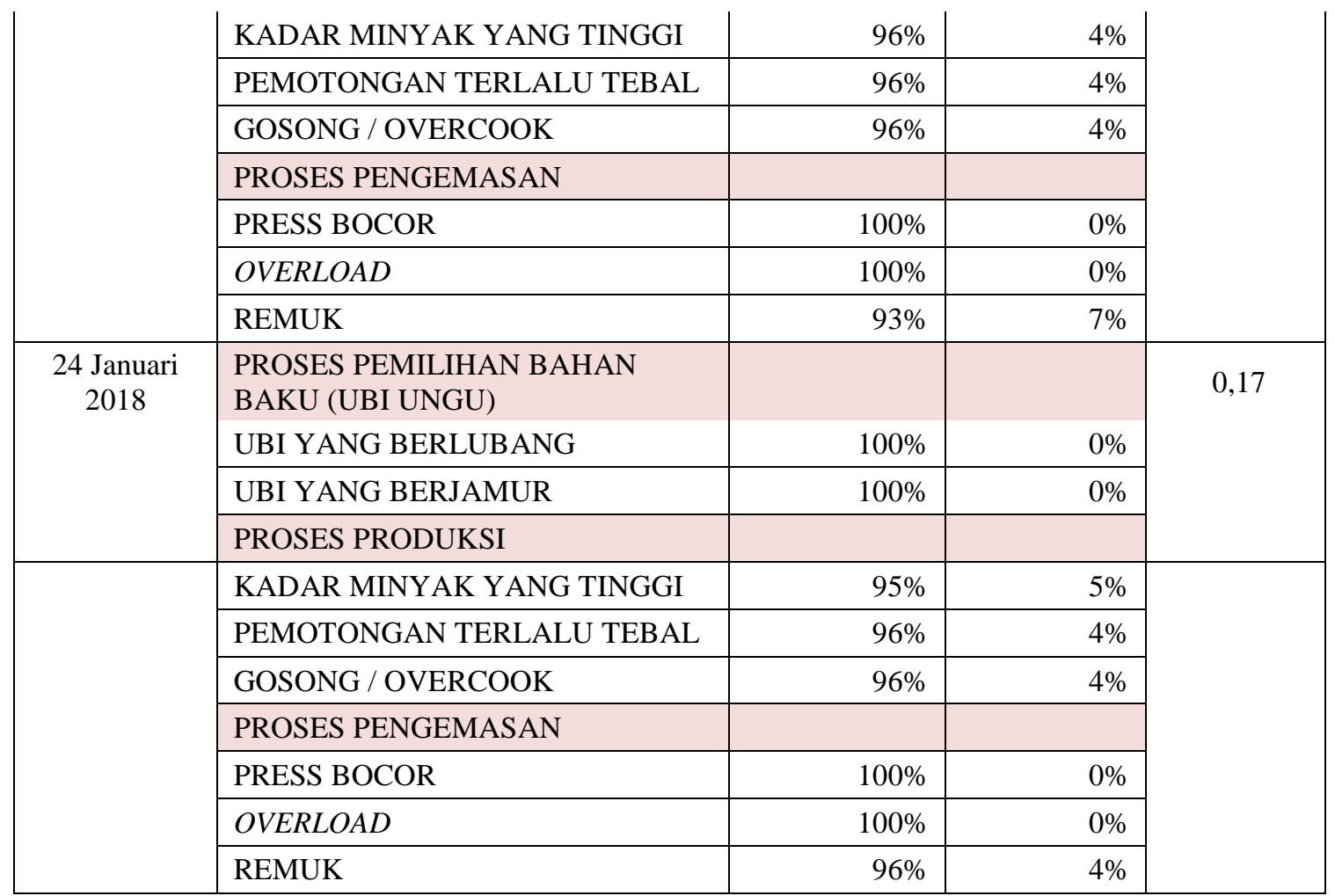

Sumber : IKM SHA-SHA (2018)

Berdasarkan table di atas di ketahui bahwa:

1. Produksi keripik ubi ungu kemasan Rp. 5000,- an pada IKM SHA-SHA selama 1 bulan ada 8 kali observasi. Untuk mempermudah penghitungan peneliti membuat presentase $100 \%$ pada setiap item produksi.

2. Tingkat ketidaksesuaian keripik ubi ungu pada IKM SHA-SHA terjadi proses produksi dan packing.

3. Untuk perhitungan proporsi cacat pada Check Sheet Produksi Keripik Ubi Ungu Pada IKM SHA-SHA pada Bulan Januari dapat di lihat pada lampiran.

\section{Pembahasan}

Pada analisis data yang dilakukan selama 1 bulan (8 kali observasi) pada proses produksi keripik ubi ungu IKM $S H A-S H A$ terbukti bahwa:

1. Berdasarkan penjabaran cara pengendalian kualitas terhadap proses produksi yang terjadi pada IKM SHA-SHA. Dengan demikian pengendalian mutu pada proses produksi keripik ubi ungu pada IKM SHA-SHA telah menghasilkan produk yang bermutu dan aman untuk dikonsumsi terbukti. 
2. Berdasarkan diagram pareto selama satu bulan penelitian (8 observasi) terdapat ketidaksesuaian (kecacatan) yang dominan yaitu remuk. Dengan demikian jenis kecacatan yang paling dominan pada produk keripik ubi ungu IKM SHA-SHA adalah cacat karena patah remuk terbukti.

3. Berdasarkan grafik kendali grafik kendali pada proses produksi IKM SHA-SHA bulan Januari 2018 di dapat nilai CL (central line) sebesar 0,19 dan niali UCL (upper control limit) sebesar 0.31 sedangkan LCL (lower control limit) sebesar 0,07). Dapat dilihat bahwa proporsi cacat (ketidaksesuaian) yang terjadi pada proses produksi keripik ubi ungu IKM SHA-SHA di bulan Januari 2018 (8 kali observasi) dalam keadaan terkendali karena semua titik berada diantara batas kendali. Dengan demikian pengendalian kualitas produk keripik ubi ungu di IKM $S H A-S H A$ masih berada pada batas kendali terbukti.

Secara umum penyebab utama terjadinya kecacatan atau ketidaksesuaian produk berasal dari faktor manusia dan mesin. Hal ini sesuai dengan penelitian terdahulu yang dilakukan oleh Darsono (2013) dan Zulfani Nooor (2015).

Pada analisis data diagram pareto diatas sesuai dengan pendapat Vilfredo Frederigo Samoso tentang diagram pareto bahwa dengan meningkatkan $20 \%$ penyebab utama dapat mengatasi $80 \%$ masalah yang muncul.

\section{KESIMPULAN}

Kesimpulan dalam penelitian ini berdasarkan pada hasil analisis data dan pembahasan yang telah dijelaskan oleh peneliti pada bab sebelumnya. Kesimpulan yang dapat diambil dalam penelitian ini adalah sebagai berikut:

Pengendalian kualitas produksi pada IKM SHA-SHAdengan produk keripik ubi ungu kemasan Rp.5000,-an sebanyak 1600 bungkus dalam 1 bulan produksi, terbukti menghasilkan produk yang bermutu dan aman dikonsumsi. Walaupun ada sedikit kecacatan atau ketidaksesuaian produk, yaitu dengan jenis ketidaksesuaian terdapat pada proses produksi dan pengemasan. Dan penyebab utama terjadinya kecacatan atu ketidaksesuaian produk berasal dari faktor manusia dan mesin 
Hasil akhir analisis Statistical Quality Control (SQC) dengan metode grafik kendali diketahui dapat dilihat bahwa proporsi cacat (ketidaksesuaian) yang terjadi pada proses produksi keripik ubi ungu IKM SHA-SHA di bulan Januari 2018 (8 kali observasi) dalam keadaan terkendali karena semua titik berada diantara batas kendali.

\section{DAFTAR PUSTAKA}

Anthony, R. and Govinndarajan, V. (2013) Sistem Pengendalian Manajemen. Jakarta: Salemba Empat.

Arianti, M. S. (2016) 'Analisis Quality Control Untuk Menjaga Kualitas Produk Tempe Pada Usaha Home Industri Tempe Bapak Joko Purwanto Di Kelurahan Lok Bahu Kecamatan Sungai Kunjang Samarinda', 4(4), pp. 1016-1030.

Darsono (2013) 'analisis pengendalian kualitas produksi dalam upaya mengendalikan tingkat kerusakan produk', (35), pp. 1-17.

Gaspersz, V. (2012) Total Quality Manajement. Jakarta: Gramedia.

Heizer, J. and Render, B. (2009) Operations Manajement. 2nd edn. Jakarta: Salemba Empat.

Kusuma, H. (2009) Manajemen Produksi: Perencanaan dan Pengendalian Produksi. Yogyakarta: Andi.

Lestari, P. R. (2018). No TitlePengaruh dimensi kepribadian The Big Five personality terhadap Organizational Citizenship Behavior (OCB), 3(1), 87-103.

Noor, Z. (2015) 'analisis pengendalian mutu untuk mencapai standar kualitas produk corn chips di pt anugerah citra era food'.

Prawirosentono, S. (2012) Manajemen Mutu Terpadu. Jakarta: Bumi Aksara.

Puspita, N. V., \& Santoso, A. (2017). Pengaruh Spread Suku Bunga, Car, Dan Npl

Terhadap Penyaluran Kredit Ukm Kota Kedir (Studi Pada Perbankan Kota Kediri). Ekonika: Jurnal Ekonomi Universitas Kadiri, 2(1).

Sugiyono (2016) Metode Penelitian Manajemen. Bandung: Alfabet.

Tjiptono, F. and Diana, A. (2013) TQM (Total Quality Manajemen). Yogyakaarta: Andi.

Winardi (2011) Ekonomi Manajerial. Jakarta: Mandar Maju. 